\title{
Shifting Borderland of Technoscience: Tracing Trajectories of Critical Practice
}

\author{
Silvia Lindtner \\ University of Michigan \\ Ann Arbor, MI 48109, USA \\ lindtner@umich.edu \\ Hrönn B Holmer \\ Cornell University \\ Ithaca, NY 14853, USA \\ hb47@cornell.edu
}

\author{
Marisa Leavitt Cohn \\ IT-Universitetet i København \\ 2300 København S, DK \\ marisa@itu.dk
}

\author{
Lucian Leahu \\ IT-Universitetet i København \\ 2300 København S, DK \\ lucian@itu.dk
}

\author{
Carl DiSalvo \\ Georgia Institute of Technology \\ Atlanta, GA 30308, USA \\ carl.disalvo@lm.gatech.edu
}

\begin{abstract}
Since the publication of Phil Agre's [1] seminal work on critical technical practice, the sites of intersection between computation and society have multiplied, and so too have the sociotechnical borderlands we inhabit. Critical methodologies such as "critical design" $[8,6,5]$, "reflective design" [3,4,7,9,15,12], "critical making" [11,6,7], "located accountability" [13, 14], "feminist HCI" [2], and "postcolonial computing" [10] have proliferated and are being taken up in increasingly diverse political, cultural and social contexts. As the sites of critical praxis have multiplied, new regimes like big data and social computing pose new challenges. Given the fluidity of the landscape it is important for us to articulate the specificities of our scholarly borderlands. By bringing together junior and senior scholars we aim to provide a forum for researchers in this area to learn from each other how to navigate changing terrains of technology research and design. To maximize indepth collaboration between junior and senior scholars, we propose a format that includes in-depth mentoring sessions, panel presentations from junior and senior participants, group activities, and working sessions for steps forward. The goal of the proposed workshop is to foster cohesion and build mentoring relationships within the community by creating a space for open and honest dialogue about the challenges of conducting critical research and design practice. Outcomes from this workshop will be a shared knowledge base about praxis, tracing the trajectories, continuities, traversals and inheritances of critical sociotechnical research over the past decade, as well as strengthening of the critical technical practice community by way of establishing lasting mentorship relations.
\end{abstract}

Copyright $(2015$ is held by the author(s). Publication rights licensed to Aarhus University and ACM

5th Decennial Aarhus Conference on Critical Alternatives August 17 - 21, 2015, Aarhus Denmark

DOI: http://dx.doi.org/10.7146/aahcc.v1i1.21471

\begin{abstract}
Author Keywords
Critical technical practice; critical making; critical design; critical computing; social computing; reflective design; located accountability; feminist HCI; research community; sociotechnical studies; interdisciplinarity.
\end{abstract}

\section{ACM Classification Keywords}

K.2. Computing Milieux: History of Computing - People.

INTRODUCTION TOPIC AND RATIONALE

The Århus Decennial conference offers a unique space to gather together junior and senior scholars whose research sits at the intersection of social, technical, and critical scholarship. Straddling multiple worlds, this kind of research involves distinctive opportunities and challenges. As Phil Agre wrote in his seminal piece on critical technical praxis such research means keeping "one foot planted in the craft work of design and the other foot in the reflective work of critique."

Since Agre's work was published, the sites of intersection between computation and society have multiplied, and so too have the sociotechnical borderlands we inhabit. Critical methodologies such as "critical design" $[8,6,5]$, "reflective design" [3,4,7,9,15,12], “critical making" [11, 7, 6], "located accountability" [13,14], "feminist HCI" [2], and "postcolonial computing" [10]. These critical methodologies have been taken up into increasingly diverse political, cultural and social contexts bringing critical practice to the worlds of policy and consulting work, to design and engineering, to start-ups and maker culture, to the politics of machine learning, and so on.

As the sites of critical praxis have multiplied, new regimes for performing critical praxis have appeared. While today it might still be possible to engage in critical work in ways similar to Agre's - e.g., in an academic AI lab - the trajectories of computational systems and infrastructures of the past decade increasingly challenge this mode of performing critical technical work. For example, computational endeavors such as big data and social computing often locate technical as well as financial 
resources with corporate actors. To obtain access to data and other resources, academic practitioners interested in critical work in these domains must partner with relevant (e.g., corporate) entities. In other words, to critically intervene in these domains one must be located either within the structures governing these resources or must enter into partnership with them.

Given these constantly changing landscapes it is important for us to articulate the specificities of our scholarly borderlands: where are we now and how did we get here? How has the terrain shifted over the past 10 years? Where might we be headed? What have we resolved and what are challenges for critical scholarship today? How can we introduce and train junior scholars amidst these shifting terrains?

This workshop aims to provide a forum for researchers in this area to learn from each other how to navigate changing terrains of technology research and design. By articulating and sharing our own trajectories, we hope to build cohesion and foster mentorship relations within the community.

\section{WORKSHOP GOALS AND THEMES}

The goal of the workshop is to foster cohesion and build mentoring relationships within the community of critical sociotechnical research by creating a space for open and honest dialogue about the challenges of conducting critical research and design practice. In particular, we want to use the unique occasion of the Århus Decennial conference to foster engagement between junior and senior scholars in the field, with the hopes that sharing knowledge, strategies, and tactics across generations will foster new opportunities for mentorship and collaboration. We aim to use the workshop to trace out trajectories of critical praxis as encountered by the workshop participants over the duration of their careers, to help articulate the conditions and stakes of the shifting sites of critical technical research and practice, and to help scholars just entering the field to navigate their own sites and encounters. As such, our aims are three fold:

Create a space for sharing knowledge about praxis. Taking inspiration from Agre's piece on critical technical practice, we will ask scholars to articulate the sociotechnical borderlands they have inhabited and how these have shifted over time. Agre's piece exemplifies situated knowledges that do not often make it to publication. Therefore we aim to create a forum for discussing the practical empirical and theoretical work that goes into crafting these multi-faceted sites/encounters between the critical and the technical. We will particularly encourage experienced scholars in the field to contribute based on their long-term engagements.

Trace the trajectories, continuities, traversals, inheritances of critical sociotechnical research over the past decade. Lucy Suchman once reflected that she began to truly appreciate her interdisciplinary encounters during the 1980 s only many years later [13]. Understanding these encounters can be a career-long pursuit, as we do not often understand their nature immediately. For this reason, we aim to open up a space to reflect on individual and collective trajectories rooted in our earlier sociotechnical encounters. We ask: what can be learned from looking back and reflecting upon the conditions/sites of critical technical work a decade ago, and how can we use this to help makes sense of where they are today?

Build cohesion and lasting mentorship relations. One attribute of critical technical work is that it tends to renew itself continually to keep up with the pace of new technologies and the flux of a shifting landscape. An emphasis on praxis helps to cut across these domains to build cohesion and to strengthen the critical technical practice community. Each researcher may be active in different fields (healthcare, media, big data, hacking, etc.) with their respective sociotechnical entanglements - yet we believe there are challenges of praxis that resonate across these various sites, which can serve to build cohesion and lasting mentor relations.

In order to generate discussion, we pose the following thematic questions:

1. In what political, cultural, economic, and institutional borderlands do we as researchers, scholars, students, mentors, teachers, and practitioners of technology operate today? How have these shifted since the last Århus conference took place in 2005 ?

2. How do we situate ourselves critically within these borderlands? In what sites do we locate possibilities for criticality? What is at stake in the particular boundaries we work with or translate across - disciplinary or institutional?

3. How do we critically craft these borderlands in the current research landscape, through "worldings," encounters and partnerships? Through what kinds of partnerships within and outside academia do we forge sites of critical praxis?

4. How do we navigate the multiple accountabilities of our research engagements and commitments within current structures of academic publishing, funding, and teaching?

By exploring these questions during the workshop, we aim to build up shared knowledge by tracing the trajectories of critical technical research over the past decade and to foster engagements between junior and senior scholars. Our underlying goal is to understand how the borderlands of our scholarship and wider practices and cultures in which we each locate our work have shifted or remained the same. While the space for critical scholarship in technical 
research, computing and design has opened, other challenges remain. For instance, funding avenues are increasingly diminishing across the EU and in the United States, pressures on individual productivity is increasing, and the corporatization of universities is in full swing At the same time, critical practice is proliferating way beyond academia. For instance, both the corporate sphere and government agencies are increasingly sites for critical engagement. How does the opening of new sites shift the borders of practice, and what are the implications for research and pedagogy? Put directly, what is stake in the encounters of the social and the technical today, and how does this relate to the borderlands encountered in earlier decades? Have fractures been smoothed over, shifted to new locales, been renewed, or put to rest?

A sign of increasing legitimacy can be seen when the students emerging from these interdisciplinary spaces embark on careers. But with these successes come new questions of how to navigate the infrastructures of funding, teaching, and writing. What are the emergent forms of accountability to which we must articulate our research? Are there new challenges or possibilities emerging within the reconfigured constellations of research, teaching and funding?

\begin{tabular}{|c|l|}
\hline \multicolumn{2}{|l|}{ Agenda } \\
\hline 8:30-9:00 & Intro: themes, goals, critical questions, ice breakers \\
\hline 9:00-10:00 & Panel - current streams of CrHCI \\
\hline 10:00-10:15 & Coffee break \\
\hline $10: 15-11: 00$ & Small group discussion \\
\hline $11: 00-12: 00$ & Mentoring session 1 \\
\hline 12:00-1:00 & Lunch \\
\hline 1:00-2:00 & Panel - Emerging Challenges \\
\hline $3: 00-3: 45$ & Small group work \\
\hline $3: 45-4: 00$ & Coffee Break \\
\hline 4:00-5:00 & Mentoring session 3 \\
\hline $5: 00-6: 00$ & Group discussion \\
\hline $7: 00-e n d$ & Adjourn, Workshop dinner \\
\hline
\end{tabular}

\section{WORKSHOP RECRUITMENT STRATEGY}

We hope to attract 20-25 participants who are currently working in the context of critical computing. We will aim for a ratio of 2-3 junior participants for each experienced participant to facilitate mentoring. We will encourage submissions from people working in areas such as anthropology, media studies, information science, sociology, design and making, and science and technology studies as these areas all have contributed to critical approaches to computing. The organizers straddle these areas and therefore have access to necessary channels to circulate the call, elicit submissions and access both senior and junior scholars in this domain of work. We will set up a workshop website where we will post workshop information, call for papers, prospective agenda and workshop papers. We will also create a Google group to foster discussion prior to the workshop.

\section{OUTCOMES}

Results from the workshop will be written up, documented and archived on a custom website, dedicated to the workshop. Beyond the conference, we aim to foster a nascent community of scholars concerned with critical computing scholarship and practice and we will use the occasion of the workshop to do so. We will also establish an email list for conversations to begin prior to the conference and plan to continue this list post-conference. We will coordinate a series of post-workshop activities such as a special issue and a handbook on critical computing. Through the Google group connection, we hope to provide the tools and connections to develop this community.

\section{ORGANIZERS}

Silvia Lindtner is an Assistant Professor at the University of Michigan in the School of Information. Her research investigates the role digital technologies play in global processes of innovation, work and labor, as sites of expressions of selfhood and collectivity, and in relation to political, social and economic processes of urban redesign. She explores these themes through a contemporary research project; maker and hacker culture, with a particular focus on its intersections with manufacturing and innovation discourse in China. She has published in various disciplines such as HCI, STS, and China studies, and has organized numerous workshops at Ubicomp and $\mathrm{CHI}$ as well as international workshops on making cultures.

Marisa Cohn is an Assistant Professor at the IT University of Copenhagen, in the Technologies in Practice and Interaction Design research groups. Her research draws on anthropology, STS, and information studies to understand software as a cultural artifact, focusing on sociotemporal entanglements in long-lived science infrastructure. She has organized workshops and panels on ethnographic and interdisciplinary methods, code studies, and design authority at venues such as 4S, DIS, CalIT2, and Art Center for Design. 
Lucian Leahu is an Assistant Professor at the IT University of Copenhagen, in the Interaction Design and Technologies in Practice research groups. His research draws on computer and information science, design, and STS to explore novel ways of relating to technology made possible by the vast and varied kinds of data available today and by computational approaches such as machine learning and big data.

Hrönn Brynjarsdóttir Holmer is a $\mathrm{PhD}$ candidate in the department of Information Science at Cornell University. Her research focuses on the politics of information, creation of data and data modeling as it pertains to natural resource management in the Icelandic fishery. To that end she has engaged in ethnographic fieldwork since 2009, interviewing a wide range of stakeholders in the fishery, observing and participating in work on board freezer trawlers and danish seine vessels as well as conducting historical archival research.

Carl DiSalvo is an Associate Professor in the Digital Media Program in the School of Literature, Communication, and Culture at the Georgia Institute of Technology. His research draws together the humanities, science and technology studies, and design to increase public engagement with technology and analyze the social and political uses of digital media.

\section{REFERENCES}

1. Agre, P., 1997. Toward a Critical Technical Practice: Lessons Learned in Trying to Reform Al. Social science, technical systems, and cooperative work: Beyond the Great Divide, p.131.

2. Bardzell, S., 2010. Feminist HCI: taking stock and outlining an agenda for design. In Proceedings of the 28th international conference on Human factors in computing systems. pp. 1301-1310.

3. Bødker, S., 2006. When second wave HCI meets third wave challenges. In Proceedings of the 4th Nordic conference on Human-computer interaction: changing roles. pp. 1-8.

4. Coleman, G. 2012. Anonymous and I [Guest contributor] post on ethnography matters. http://ethnographymatters.net, last accessed October, 2012.

5. DiSalvo, C., Nourbakhsh, I., \& Holstius, D. (2008). The neighborhood networks project: A case study of critical engagement and creative expression through participatory design.

6. Dunne, A. and Raby, R. 2001. Design Noir: The Secret Life of Electronic Objects, Springer.

7. Leahu, L., Thom-Santelli, J., Pederson, C., Sengers, P. 2004. Taming the Situationist Beast. In Proceedings of the $7^{\text {th }}$ ACM Conference on Designing Interactive Systems (DIS), 203-211.

8. Light, A. (2011) Democratising Technology: Inspiring Transformation with Design, Performance and Props, In Proc. of the 2011 ACM Conference on Human Factors of Computing.

9. Lindtner, S., Anderson, K., Dourish, P. 2012. Cultural Appropriation: Information Technologies as Sites of Transnational Imagination. Proc. of the ACM Conference on CSCW, Seattle, Washington.

10. Philip, K., Irani, L. \& Dourish, P., 2012. Postcolonial Computing A Tactical Survey. Science, Technology \& Human Values, 37(1), pp.3-29.

11. Ratto, M., 2011. Critical Making: conceptual and material studies in technology and social life. The Information Society, 27(4), pp.252-260.

12. Sengers, P. et al., 2005. Reflective design. In Proceedings of the 4th decennial conference on Critical computing: between sense and sensibility. pp. 49-58.

13. Suchman, L., 2002. Located accountabilities in technology production. Scandinavian Journal of Information Systems, 14(2), pp.91-106.

14. Taylor, A. 2011. Out There. In Proc. of the 2011 ACM Conference on Human Factors of Computing, 685-694.

15. Williams, A., Brewer, J., Gibb, A., Wilhelm, E., Forrest, H. 2012. Indy R\&R: Doing HCI Research Off the Beaten Path, Juried Panel at CHI 2012, Austin, TX. 